\title{
Multilocus heterozygosity and sexual selection in the brine shrimp Artemia franciscana
}

\author{
C. Zapata`, G. Gajardo“”, J. A. Beardmore \\ School of Biological Sciences, University College of Swansea, Singleton Park, Swansea SA2 8PP, United Kingdom
}

\begin{abstract}
A study to test for an association between multilocus heterozygosity and male sexual selection was conducted in an experimental population of the brine shrimp Artemia franciscana. A significant positive correlation between male mating success and heterozygosity was detected. This is the first report of an association between male sexual selection and multilocus heterozygosity. The results add to the evidence suggesting that a correlation of this type applies to all components of total Darwinian fitness. The observed correlation is interpreted in the light of the major hypotheses proposed to explain such correlations.
\end{abstract}

\section{INTRODUCTION}

In the last decade much work has been devoted to searching for correlations between multilocus heterozygosity and traits related to fitness in a variety of species including many from marine environments (see reviews by Mitton \& Grant 1984, Zouros \& Foltz 1987). Multilocus heterozygosity has been studied mainly in relation to growth rate (Zouros et al. 1980 , Ledig et al. 1983, Koehn \& Gaffney 1984, Koehn et al. 1988, Alvarez et al. 1989), but also with respect to developmental stability (Leary et al. 1983, 1984), viability (Beardmore \& Ward 1977, Zouros et al. 1983, Diehl \& Koehn 1985, Alvarez et al. 1989), fecundity (Schaal \& Levin 1976, Rodhouse et al. 1986), response to physiological stress (Koehn \& Shumway 1982) and, at an interpopulation level, a range of fitness components including fecundity (Quattro \& Vrijenhoek 1989). Positive associations between multilocus allozyme heterozygosity and fitness have, thus, frequently been detected although contrary evidence has also been reported (Mukai et al. 1974, McAndrew et al. 1982).

\footnotetext{
- Present address: Departamento de Biologia Fundamental, Facultad de Biologia, Universidad de Santiago de Compostela, Santiago de Compostela, Spain

- Present address: Departamento de Acuicultura y Alimentos, Instituto Profesional de Osorno, Casilla 933, Osorno, Chile
}

To our knowledge, the relationship between multilocus allozyme heterozygosity and male sexual selection has not yet been tested in a way comparable to other fitness components. Many studies have been addressed to examining the effect of protein variation on sexual selection but not specifically to test for an association between multilocus protein heterozygosity and sexual selection (Marinkovic \& Ayala 1975a, b, Christiansen 1977, Eanes et al. 1977. Aslund \& Rasmuson 1976, Carter \& Watt 1988). In addition, evidence based largely on data from Drosophila shows that fertility (which includes sexual selection and fecundity) is at least as important as viability in determining total Darwinian fitness (Polivanov \& Anderson 1969, Sved \& Ayala 1970, Marinkovic \& Ayala 1975a, b, Anderson et al. 1979, Brittnacher 1981). More detailed evidence from some studies indicates that sexual selection may be the most important single fitness component of net fitness (Prout 1971a, b, Bungaard \& Christiansen 1972).

The influence of heterozygosity on female reproductive success in Artemia has, however, been examined recently (Gajardo \& Beardmore 1989). The results obtained show clearly that greater heterozygosity confers both greater overall reproductive success and greater capacity to switch resources into the oviviviparous mode of reproduction.

This paper considers the relationship between multilocus allozyme heterozygosity and male sexual selection in an experimental population of Artemia franciscana. 


\section{MATERIAL AND METHODS}

Artemia material. Brine shrimps Artemia franciscana from Manaure, Guajira (Colombia) were obtained in the form of cysts from the Artemia Reference Centre in Ghent, Belgium. Cysts were mass-hatched in filtered synthetic seawater (Instant Ocean) at $20 \%$ salinity and $24{ }^{\circ} \mathrm{C}$ with fluorescent lighting and constant aeration. After $24 h$, the nauplii were transferred to a large population cage in 11 of seawater ( $90 \%$ salinity) and fed with Dunaliella tertiolecta algae cells. Prior to sexual maturity males and females were collected and placed in separate glass bottles.

Sexual selection experiment. Sexually mature virgin females (80) and males (160) were allowed to mate in a translucent plastic population cage containing 11 of seawater ( $90 \%$ salinity) and Dunaliella tertiolecta as food at $24^{\circ} \mathrm{C}$ with constant fluorescent lighting. A $1: 2$ female : male ratio was used in the mating population to ensure competition between males for access to females. At intervals during a $44 \mathrm{~h}$ observation period, mating pairs were carefully collected with an aspirator and put into separate numbered vials, noting the time at which mating took place. In this way, we could monitor how the mating population was changing during the experiment. Mating pairs were easily identifiable as males clasp females dorsally for periods of up to several days. Mating pairs and unmated individuals were stored at $-60^{\circ} \mathrm{C}$ until electrophoretic analysis could be carried out.

Sample. Of 240 individuals used to initiate the experiment, 12 died during the experiment while 76 mated pairs and 76 unmated males were recovered. Of these 228 survivors, only 207 individuals were used for analysis. The difference between 228 and 207 is accounted for, almost wholly, by the occasional failure of a zymogram for one system in one individual to give a clear phenotype. When this happened to one member of a mated pair, both were removed from the analysis. Thus 69 mating pairs and 69 unmated males (207 individuals in total) were ultimately used for analysis after being typed for the 5 allozyme loci. Because all the surviving females had mated during the experiment, female sexual selection could not be examined and therefore we consider only the other 2 components of mating behaviour - male sexual selection and pattern of mating - in the analysis of the effect of heterozygosity at single and multiple loci on mating structure

Mating structure is here tested by a multiple choice experiment, i.e. with a large number of males and females together, a situation reasonably close to that found in nature. Marking procedures were not necessary to distinguish the mating pairs and this enables possible artefactual results (Bryant et al. 1980) to be avoided.
Starch gel electrophoresis. Individuals were electrophoresed in starch gels following the procedures described in Abreu-Grobois \& Beardmore (1980). For each individual, the genotypes at 5 polymorphic loci were determined. These were the loci coding for esterase-D (Est-D, EC 3.1.1.1), isocitrate dehydrogenase (2 loci: Idh-1, Idh-2, EC 1.1.42), 6-phosphogluconate dehydrogenase (6-Pgd, EC 1.1.1.44) and phosphoglucose isomerase (Pgi, EC 5.3.1.9).

Analysis of mating behaviour. Mating performance in relation to single allozyme loci and multilocus allozyme genotypes was examined in terms of the 3 principal components contributing to mating behaviour, namely: differential male mating success, differential female mating success and pattern of mating. Statistical tests of divergence from the null hypotheses, i.e. no male and female sexual selection and random mating, were carried out by means of the G-test (Sokal \& Rohlf 1981). The test $G$ for males $\left(G_{M}\right)$ was used to detect significant deviations of the male genotypic frequencies in observed matings (males mated) from the expectations based on the corresponding frequencies in the males of the population (mated and unmated males). The $G$-test for females $\left(G_{F}\right)$ may be computed in a similar way. Deviations from random mating were tested by contingency $G$-tests $\left(G_{R M}\right)$. The $G$-test for the total $\left(\mathrm{G}_{\mathrm{T}}\right)$ measures the deviations of the observed matings from the expected frequency of matings based on the genotype frequencies of the males and females. Given that the G-statistic is exactly additive, $G_{T}$ is equal to the sum of the 3 components $G_{M}, G_{P}$ and $G_{R M}$.

Mating success was quantified by computing fitnesses or adaptive values. Fitness estimates are obtained by comparing genotype distribution in the total population (input fequencies) and mating portion (output frequencies) by means of the cross-product ratio estimators (Cook 1971). Significant differences in genotypic frequencies between input and output distributions should indicate the operation of sexual selection. Let $N_{11}, N_{12}, \ldots, N_{1}$ and $N_{21}, N_{22}, \ldots, N_{21}$ be the observed number of individuals of the $i^{\text {th }}$ genotype in the total population $\left(\mathrm{N}_{1}\right)$ and mating portion $\left(\mathrm{N}_{2}\right)$. respectively. The mating fitness estimate $(\mathrm{W})$ of the $i^{\text {th }}$ genotype standardized to the $\mathrm{j}^{\text {th }}$ genotype (fitness equal to 1) is computed for each sex as:

$$
\hat{W}_{\mathrm{i}}=\left(\mathrm{N}_{2 \mathrm{i}} / \mathrm{N}_{2 \mathrm{j}}\right)\left(\mathrm{N}_{1 j} / \mathrm{N}_{1 \mathrm{i}}\right)
$$

It is noteworthy that this estimation procedure does not generate spurious frequency-dependent fitnesses (Alvarez et al 1984). A procedure to obtain the variance of a cross-product ratio estimator has been developed by Connolly \& Gliddon (1984) and from that and an explicit equation due to Alvarez et al. (1989), the variance of $W$ may be estimated as follows: 


$$
\begin{aligned}
\hat{V}\left(W_{1}\right)= & \frac{\hat{W}_{\mathrm{i}}}{N_{1 \mathrm{i}} N_{2 \mathrm{i}}}\left[\frac{\left(N_{1 \mathrm{i}}+N_{1 \mathrm{i}}\right)\left(N_{2 i}+N_{21}\right)}{N_{1 \mathrm{i}} N_{2 \mathrm{j}}}+\right. \\
& \left.\frac{N_{2,}\left(N_{1,}+N_{1,}\right)}{N_{1 \mathrm{i}}}+\frac{N_{1},\left(N_{2 i}+N_{21}\right)}{N_{21}}\right]
\end{aligned}
$$

As the time at which mating took place was recorded, fitness estimates can also be computed for early matings (first half of matings) and late matings (second half of matings) by cross-product ratio estimators. The fitness for early matings is computed by comparing the genotype distribution before mating with that of the first half of the matings. The fitness for later matings is obtained by comparing the genotype distribution in the yet unmated (after the first half of matings had taken place) with the genotype distribution corresponding to the second half of matings.

Some of the statistical tests were performed using the SPSS computer package.

\section{RESULTS}

\section{Heterozygosity at single loci and sexual selection}

In the population used, each allozyme locus has 2 common alleles, and 1 (Est-D, Idh-2, 6-Pgd, Pgi) or 2 (Idh-1) rare alleles (average frequency $0.028 \pm 0.006$ ). The most polymorphic locus is 6 -Pgd (38\% heterozygotes), whereas the least is Est-D (14.5\% heterozygotes). Conformity of genotype frequencies to HardyWeinberg expectations was tested by the $\chi^{2}$ test. Four of the 5 loci gave results which differed significantly from Hardy-Weinberg expectations. There was a greater than expected frequency of heterozygotes at the Idh-1 locus and lower than expected at the Idh-2, 6-Pgd and Pgi loci.

Table 1 shows the analysis by G-test of the mating behavior of males heterozygous and homozygous at each of the loci used. Also given are the frequencies of homozygous and heterozygous males before mating as well as the observed matings. The total G-statistic $\left(\mathrm{G}_{\mathrm{T}}\right)$ shows significant departures of observed matings from expectations only for the Idh-2 locus. The analysis by components shows that this is mainly due to significant deviations from random mating. The G-tests for males for Idh-2 $\left(G_{M}=3.54\right)$ and $6-P g d ~\left(G_{M}=3.21\right)$ exhibit borderline significance. We may, therefore, suspect some differential mating success between homozygous and heterozygous males for different individual loci.

Table 2 shows male sexual fitness estimates with their corresponding standard errors lobtained from the asymptotic sampling variances) of heterozygous relative to homozygous genotypes (in which fitness is set to 1). On the whole, heterozygotes exhibit fitness values higher than homozygotes with the exception of Idh-1 (Wilcoxon's signed-ranks test detects significant differences between fitness of heterozygotes and homozygotes, $\mathrm{Ts}=21.5, \mathrm{n}=15, \mathrm{p}<0.05)$. These fitness estimates are associated with large variances so that it is difficult to detect significant differences ascribable to a particular locus except when very large effects are involved (Connolly \& Gliddon 1984). Thus, taking as a significance criterion that $\left|\hat{W}_{1}-1\right|$ $>2.0$ or 2.6 standard errors (for 5 or $1 \%$ level of significance, respectively), at neither locus does the fitness of heterozygotes differ significantly from 1. Nevertheless, if mean fitness values with their corresponding standard errors are obtained from early and late mating fitnesses, heterozygous genotypes at the Idh-2 and 6-Pgd loci are seen to be significantly more successful than homozygotes, and for Idh-1 the opposite is true. When, for each locus, the fitness of the 2 homozygotes is estimated relative to the heterozygote (pooling homozygotes of similar mobility and heterozygotes with heterozygotes), evidence for overdominance arises for Idh-2 ( $\mathrm{W}_{\mathrm{AA}}=0.62, \mathrm{~W}_{\text {aa }}$ $=0.64)$ and $6-\mathrm{Pgd}\left(\mathrm{W}_{\mathrm{AA}}=0.69, \mathrm{~W}_{\mathrm{aa}}=0.56\right)$ and the heterozygote is slightly inferior for Idh-1 (WAA $=$ 1.17. $\mathrm{W}_{\mathrm{aa}}=1.10$ ). Overdominant selection for Idh-2 and 6-Pgd does not necessarily mean that selection is favouring heterozygotes for these loci as selection. may be favouring heterozygotes at closely linked

\begin{tabular}{|c|c|c|c|c|c|c|c|c|c|c|}
\hline \multirow[t]{2}{*}{ Locus } & \multicolumn{2}{|c|}{$\begin{array}{c}\text { Male frequencies } \\
\text { before mating }\end{array}$} & \multicolumn{4}{|c|}{ Matings observed (females first) } & \multicolumn{4}{|c|}{ G-test for mating behaviour } \\
\hline & Hom & Het & Hom $\times$ Hom & Hom $\times$ Het & Het $\times$ Hom & Het $\times$ Het & $\mathrm{G}_{\mathrm{M}}(\mathrm{df}=1)$ & $\mathrm{GF}(\mathrm{df}=1)$ & $\operatorname{Gr}_{\mathrm{M}}(\mathrm{df}=1)$ & $\mathrm{GT}(\mathrm{df}=3)$ \\
\hline Est-D & 125 & 13 & 46 & 6 & 16 & 1 & 0.04 & 0.00 & 0.49 & 0.53 \\
\hline Idh-1 & 81 & 57 & 29 & 19 & 14 & 7 & 0.38 & 0.00 & 0.25 & 0.63 \\
\hline Idh-2 & 93 & 45 & 31 & 15 & 8 & 15 & 3.54 & 0.00 & $6.67^{\circ}$ & $10.21^{\circ}$ \\
\hline $6-\mathrm{Pgd}$ & 96 & 42 & 20 & 11 & 21 & 17 & 321 & 0.00 & 0.61 & 3.82 \\
\hline Pgi & 112 & 26 & 46 & 14 & 7 & 2 & 0.95 & 0.00 & 0.01 & 0.96 \\
\hline
\end{tabular}

Table 1. Artemia franciscana. G-test for mating behaviour of heterozygotes and homozygotes at single allozyme loci 
Table 2. Artemia franciscana. Mating success fitness of heterozygous males at single allozyme loci relative to homozygotes (with fitness equal to 1 )

\begin{tabular}{|ccccc}
\hline Locus & All & Early & Mated males & Lean \pm SE \\
\hline Est-D & $1.09 \pm 0.55$ & $2.06 \pm 1.14$ & $0.41 \pm 0.47$ & $1.24 \pm 0.83$ \\
Idh-1 & $0.86 \pm 0.26$ & $0.88 \pm 0.35$ & $0.81 \pm 0.33$ & $0.85 \pm 0.04 \cdots$ \\
Idh-2 & $1.59 \pm 0.49$ & $1.45 \pm 0.58$ & $1.98 \pm 0.81$ & $1.72 \pm 0.27 \cdots$ \\
6-Pgd & $1.56 \pm 0.48$ & $1.60 \pm 0.64$ & $1.81 \pm 0.75$ & $1.71 \pm 0.11 \cdots$ \\
Pgi & $1.30 \pm 0.47$ & $1.12 \pm 0.54$ & $1.55 \pm 0.73$ & $1.34 \pm 0.22$ \\
. Mean values significantly different from 1.00 at 1. \% level & & \\
\hline
\end{tabular}

loci in gametic disequilibrium with those loci monitored.

The experimental design allows us to ask whether heterozygous males are at an advantage for matingspeed, an important component of fitness (Parsons 1974, Hedrick \& Murray 1983). Differences in heterozygosity between early and late mating males were tested by the G-test with Williams' correction. This was significant only for Est-D $(\mathrm{G}=4.23$, df $=1, \mathrm{p}<0.05)$. Rank-order correlation analysis using Kendall's Tau was also carried out in order to test for an association between heterozygosity at single loci and mating speed (expected to be negative if heterozygous males are at an advantage). A significant result was found only for Est-D $(\tau=-0.17, p=0.05)$. On the whole, therefore, it does not seem that heterozygotes mate more quickly.

\section{Multilocus allozyme heterozygosity and sexual selection}

Male genotypes can be classified according to the number of loci for which the individual is heterozygous (Table 3). Analysis of mating data for multilocus genotypes differing in levels of heterozygosity was also carried out for each component contributing to mating behavior. In this way, selective and non-selective agents acting on mating are clearly differentiated Pattern of mating (random, consanguineous, etc.) is a

Table 3. Artemia franciscana. Distribution of the number of heterozygous loci per individual in males before mating and in mateci males

\begin{tabular}{|ccrrr|}
\hline $\begin{array}{l}\text { Heterozygous loci } \\
\text { per individual }\end{array}$ & $\begin{array}{c}\text { Males before } \\
\text { mating }\end{array}$ & \multicolumn{3}{c|}{ Mated males } \\
All & Early & Late \\
\hline 0 & 28 & 10 & 5 & 5 \\
1 & 56 & 27 & 12 & 15 \\
2 & 39 & 19 & 11 & 8 \\
3 & 11 & 10 & 4 & 6 \\
4 & 4 & 3 & 2 & 1 \\
\hline
\end{tabular}

nonselective agent related to the choice of mate but not necessarily to mating success (Anderson \& McGuire 1978, Alvarez et al. 1984). In sexual selection, however, one of the male or female types can mate more often than others but mates at random or consanguineously depending on the pattern characteristic of the population concerned. This is not a superfluous clarification given that sexual selection has frequently been defined as a deviation from random mating. This erroneous definition causes serious problems in fitness estimation such as when a mating pattern with superior heterozygotes and with constant adaptive values can be misinterpreted as a pattern of frequency-dependent selection with variable adaptive values (Alvarez et al. 1984).

Significance for each component was tested in this case by a $\chi^{2}$ test because some possible mating pair types were undetected. This analysis showed there were no significant deviations from random mating $\left(\chi^{2}=15.14, \mathrm{df}=12, \mathrm{p}>0.20\right)$ nor significant deviations in males $\left(x^{2}=5.37\right.$, df $\left.=4, p>0.20\right)$. However, the statistical significance of the $\chi^{2}$ test is strongly dependent on the sample size, and in our case, the power of the test to detect male sexual selection if observed deviations from the null hypotheses were real is equal to 0.40 . It follows that the probability of rejecting the null hypotheses (no male sexual selection) is low and the lack of significance should, therefore, be considered with caution.

The $\chi^{2}$ test indicates whether genotypes differ significantly in mating success but does not quantify differences. However, the estimation of fitness differences between genotypes is of paramount importance in order to characterize any selection operating. Mating success has been quantified using a variety of indices (Spieth \& Ringo 1983, Knoppien 1985), but it can best be measured in terms of relative adaptive values which have a genuine biological meaning (Santos et al. 1986)

Table 4 gives fitness values, with their standard errors, for the different multilocus heterozygosity classes. Fitnesses are estimated by means of cross-product 
ratio estimators and standard errors are obtained from asymptotic sampling variances. Fitness estimates for multilocus allozyme genotypes differing in degree of heterozygosity are computed for each set of matings (early matings, late matings and all matings). As a first approximation it can be said that males heterozygous for one or more loci always exhibit fitness values greater than those homozygous for all loci (sign test, $\mathrm{p}<0.01)$. In addition, the mean fitness of males heterozygous for one or more loci is significantly different from the fitness of homozygotes, irrespective of the set of matings considered. For each non-zero heterozygosity class the fitness for males averaged over early and late matings is significantly different from that of homozygotes. It seems clear, therefore, that heterozygous males are more successful in mating than homozygous males. However, no evidence exists for an advantage of heterozygotes in mating speed. The Gtest does not detect significant differences between heterozygosity distributions in early and late mated males $(G=1.43, \mathrm{df}=4, \mathrm{p}>0.80)$ and the degree of heterozygosity in males does not correlate with the time taken to mate ( $\tau=-0.02, p=0.85$ ).

On the other hand, we can examine whether a relative increase in heterozygosity correlates with a relative increase in male mating success. The Kendall coefficient of rank correlation between male sexual fitness and degree of heterozygosity is close to significance for all matings ( $\tau=0.80, p=0.08$ ) and is significant for early matings $(\tau=1.00, p=0.02)$ in spite of the fact that the number of pairs available for statistical analysis is low. If early and late matings are considered in the same correlation analysis, the number of pairs increased and, in this case, the correlation is highly significant $(\tau=0.80, p<0.01)$. In all cases heterozygosity correlates positively with male sexual selection, i.e. more heterozygous males tend to be more successful in mating.

\section{DISCUSSION}

Three major hypotheses have been advanced to explain the association between heterozygosity and fitness traits (Ledig et al. 1983. Smouse 1986, Zouros \& Foltz 1987, Koehn et al. 1988). The loci monitored are then themselves responsible for the fitness differences observed (overdominance hypothesis) or are neutral genes in gametic disequilibrium with closely linked selective loci (associative overdominance hypothesis) or are neutral markers of the heterozygosity of the total genome (inbreeding depression hypothesis). In this regard, it is necessary to emphasize that the overdominance hypothesis does not satisfactorily explain the correlation between heterozygosity and male sexual selection detected in the present study. The differences in estimates of male mating success associated with heterozygosity at only a few allozyme loci (Table 4) are too large to allow this. Thus, average selection coefficients relative to the fittest heterozygosity class are 0.43 $\pm 0.09,0.48 \pm 0.08$ and $0.61 \pm 0.07$ for all, early and late matings, respectively. It seems very unlikely that these large selective effects are due exclusively to the effect of only 5 allozyme loci. Such large selective effects associated with heterozygosity classes based on small numbers of loci are not unusual. Thus, the magnitude of the selection coefficients in mating success reported here is similar to that reported for viability in marine molluscs (Alvarez et al. 1989). In 3 species of bivalves, Crassostrea virginica, Ostrea edulis and Mytilus edulis, viability selection coefficients for heterozygosity classes based on only 3 to 5 allozyme loci were close to 0.50 .

An explanation of how heterozygosity affects sexual selection may be given in physiological terms. Evidence derived mainly from marine molluscs shows that a positive relationship between observed growth and multilocus heterozygosity is associated with a negative relationship between routine metabolic costs and

Table 4. Artemia franciscana. Male mating success as a function of allozyme heterozygosity

\begin{tabular}{|c|c|c|c|c|c|c|c|c|c|}
\hline \multirow{2}{*}{$\begin{array}{l}\text { Mated } \\
\text { males }\end{array}$} & \multicolumn{5}{|c|}{ Degree of heterozygosity } & \multirow{2}{*}{$\begin{array}{c}\text { Mean male sexual fitness } \\
\text { of heterozygotes }\end{array}$} & \multicolumn{3}{|c|}{ Correlation } \\
\hline & 0 & 1 & 2 & 3 & 4 & & $\mathrm{~N}$ & $\tau$ & $P$ \\
\hline All & 1 & $\begin{array}{r}1.35 \\
\pm 0.60\end{array}$ & $\begin{array}{r}1.36 \\
\pm 0.64\end{array}$ & $\begin{array}{r}2.54 \\
\pm 0.51\end{array}$ & $\begin{array}{r}2.10 \\
\pm 1.93\end{array}$ & $1.84 \pm 0.29 \cdots$ & 5 & 0.80 & 0.08 \\
\hline Early & 1 & $\begin{array}{r}1.20 \\
\pm 0.71\end{array}$ & $\begin{array}{r}1.58 \\
\pm 0.96\end{array}$ & $\begin{array}{r}2.04 \\
\pm 1.62\end{array}$ & $\begin{array}{r}2.80 \\
\pm 3.05\end{array}$ & $1.91 \pm 0.34^{*}$ & 5 & 1.00 & 0.02 \\
\hline Late & 1 & $\begin{array}{r}1.57 \\
\pm 0.93\end{array}$ & $\begin{array}{r}1.31 \\
\pm 0.86\end{array}$ & $\begin{array}{r}3.94 \\
\pm 3.11\end{array}$ & $\begin{array}{r}2.30 \\
\pm 3.56\end{array}$ & $2.28 \pm 0.59^{\circ}$ & 5 & 0.60 & 0.23 \\
\hline \multicolumn{10}{|c|}{ Early and late pooled: } \\
\hline Mean $( \pm S E)$ & 1 & $\begin{array}{r}1.39 \\
\pm 0.19\end{array}$ & $\begin{aligned} & 1.45 \\
\pm & 0.14^{\cdots}\end{aligned}$ & $\begin{aligned} & 2.99 \\
\pm & 0.95^{\circ}\end{aligned}$ & $\begin{aligned} & 2.55 \\
\pm & 0.25 \cdots\end{aligned}$ & $2.10 \pm 0.40^{\circ}$ & 9 & 0.80 & $<0.01$ \\
\hline
\end{tabular}


increasing heterozygosity (Koehn \& Shumway 1982, Garton et al. 1984, Diehl et al. 1985). Thus, a reduction in the energy requirement for maintenance metabolism in more heterozygous individuals may result in an increase in the amount of energy available for growth or reproduction. Heterozygosity-dependent energetic advantage may indeed be manifested in other energy-dependent traits. Rodhouse et al. (1986) demonstrated a negative correlation between multilocus allozyme heterozygosity and fecundity in the mussel Mytilus edulis. However, this correlation was confined to older individuals and was not observed in younger mussels. They concluded that the higher scope for growth of more heterozygous mussels is translated into allocation of energy to somatic growth during early life and into gamete production in the later life of the organism. These results could also explain why, in other studies, the correlation between growth rate and heterozygosity is reflected most clearly in younger individuals (Diehl \& Koehn 1985). Results showing a more clear-cut relation between heterozygosity and reproductive output come from the work of Gajardo \& Beardmore (1989) on female Artemia and that of Quattro and Vrijenhoek (1989) on Poecilopsis. The results of these workers demonstrate clearly that in these species the more heterozygous individuals are able to devote a larger amount of energy to the production of progeny.

Such a physiological explanation for a fecundityheterozygosity correlation can readily be extended, to explain the correlation of heterozygosity with other energy-dependent fitness traits operating in the adult phase of the life cycle such as sexual competition for partners.

A relationship between multilocus allozyme heterozygosity and traits related to fitness is well documented for a variety of species (Mitton \& Grant 1984 , Zouros \& Foltz 1987). In many cases heterozygosity correlates positively with components of total fitness. However, very little work has been done to test association between multilocus heterozygosity and sexual selection. In this paper, we provide evidence for an association between heterozygosity and male mating success in the brine shrimp and we argue that the correlation is likely to involve all components of total. fitness. Clearly, more studies on the association between multilocus heterozygosity and sexual selection in other species are needed in order to test the generality of this phenomenon. For marine species the knowledge obtained from such studies will both aid understanding in problems of fundamental population biology and be useful in a variety of aspects of mariculture.

Acknowledgements. Comments on the manuscript by $G$. Alvarez are greatly appreciated. C. Z. was supported by a fellowship from the Xunta de Galicia and G. G. was supported by a fellowship from the British Council both of which are gratefully acknowledged.

\section{LITERATURE CITED}

Abreu-Grobos, F. A., Beardmore, J. A. (1980). International study on Artemia II. Genetic characterization of Artemia populations: a electrophoretic approach. In: Persoone, G., Sorgeloos, P., Roels, C., Jaspers, E. (eds.) The brine shrimp Artemia, Vol. 1 Morphology, genetics, radiobiology, toxicology. Universa Press, Wetteren, p. 133-146

Alvarez, G., Santos, M., Zapata, C. (1984). Frequency-dependent selection arising from inappropriate fitness estimation. Evolution 38: 696-699

Alvarez, G., Zapata, C., Amaro, R., Guerra, A. (1989). Multilocus heterozygosity at protein loci and fitness in the European oyster, Ostrea edulis L. Heredity 63: 359-372

Anderson, W W., Levine, L., Olvera, O., Powell, J. R., De La Rosa, M. E., Salceda, V. M., Gaso, M. I., Guzman, J. (1979). Evidence for selection by male mating success in natural populations of Drosophila pseudoobscura. Proc natn. Acad. Sci. U.S.A. 76: 1519-1523

Anderson, W. W. McGuire, R. R. (1978). Mating pattern and mating success of Drosophila pseudoobscura karyotypes in large experimental population. Evolution 32: 416-423

Aslund, S.-E., Rasmuson, M. (1976). Mating behaviour as a fitness component in maintaining allozyme polymorphism in Drosophila melanogaster. Hereditas 82: 175-178

Beardmore, J. A., Ward, R. D. (1977). Polymorphism, selection, and multilocus heterozygosity in the plaice, Pleuronectes platessa L. In: Christiansen, F. O., Fenchel, T M. (eds.) Lecture notes in biomathematics, Vol. 19. Measuring selection in natural populations. Springer-Verlag, New York, p. 207-221

Brittnacher, J. G. (1981). Genetic variation and genetic load due to the male reproductive component of fitness in Drosophila. Genetics 97: 719-730

Bryant, E. H., Kence, A., Kimball, K. T. (1980). A rare-male advantage in the housefly induced by wing clipping and some general considerations for Drosophila. Genetics 96: 975-993

Bundgaard, J., Christiansen, F. B. (1972). Dynamics of polymorphisms. I. Selection components in an experimental population of Drosophila melanogaster. Genetics 71 . $439-460$

Carter, P. A., Watt, W. B. (1988). Adaptation at specific loci. V Metabolically adjacent enzyme loci may have very distinct experiences of selective pressures. Genetics 119: 913-924

Christiansen, F. B. (1977). Population genetics of Zoarces viviparus (L.): a review. In: Christiansen, F. O., Fenchel, T M. (eds.) Lecture notes in biomathematics, Vol. 19. Measuring selection in natural populations. Springer-Verlag, New York, p. 21-47

Connolly, J., Gliddon, C. (1984). On the estimation of viabilities in competition experiments. Heredity 53: 527-543

Cook, L. M. (1971). Coefficients of natural selection. Hurchinson Univ. Library, London

Diehl, W J., Gaffney, P. M., McDonald, J. H., Koehn, R. K. (1985) Relationship between weight-standardized oxygen consumption and multiple-locus heterozygosity in the mussel, Mytilus edulis. In: Gibbs, P. (ed.) Proc. 19th European Marine Biology Symposium. Cambridge University Press, Cambridge, p. 529-534

Diehl, W. J., Koehn, R. K. (1985). Multiple-locus heterozygosity, mortality, and growth in a cohort of Mytilus edulis. Mar. Biol. 88: 265-271

Eanes, W. F., Gaffney, P. M., Koehn, R. K., Simon, C. M. (1977). A stucly of sexual selection in natural populations of the milkweed beetle, Tetraopes tetraophthalmus. In: Christıansen, F. O. Fenchel, T M. (eds.) Lecture notes in 
biomathematics, Vol. 19. Measuring selection in natural populations. Springer-Verlag, New York, p. 49-64

Gajardo, G., Beardmore, J. A. (1989). Ability to switch reproductive mode in Artemia is related to maternal heterozygosity. Mar. Ecol. Prog. Ser. 55: 191-195

Garton, D. W., Koehn, R. K. Scott, T. M. (1984). Multiple-locus heterozygosity and the physiological energetics of growth in the coot clam, Mulinia lateralis, from a natural population. Genetics 108: 445-455

Hedrick, P. W. Murray, E. (1983). Selection and measures of fitness. In: Ashburner, M., Carson, H. L., Thompson. J. N. Jr (eds.) The genetics and biology of Drosophila, Vol. 3d. Academic Press, New York, p. 61-104

Knoppien, P. (1985). Rare male mating advantage: a review. Biol. Rev. 60: 81-117

Koehn, R. K., Diehl, W. J., Scott, T M. (1988). The differential contribution by individual enzymes of glycolysis and protein catabolism to the relationship between heterozygosity and growth rate in the coot clam, Mulinia lateralis. Genetics 118: 121-130

Koehn, R. K., Gaffney, P. M. (1984). Genetic heterozygosity and growth rate in Mytilus edulis. Mar. Biol. 82: 1-7

Koehn, R. K., Shumway, S. E. (1982). A genetic/physiological explanation for differential growth rate among individuals of the American oyster, Crassostrea virginica (Gmelin). Mar. Biol. Lett. 3: 35-42

Leary, R. F., Allendorf, F. W., Knudsen, K. L. (1983). Developmental stability and enzyme heterozygosity in rainbow trout. Nature, Lond. 301: 71-72

Leary, R. F., Allendorf, F. W., Knudsen, K. L. (1984). Superior developmental stability of heterozygotes at enzyme loci in salmonid fishes. Am. Nat. 124: 540-551

Ledig, F. T., Guries, R. P., Bonefeld, B. A. (1983). The relation of growth to heterozygosity in pitch pine. Evolution 37 : $1227-1238$

Marinkovic, D., Ayala, F. J. (1975a). Fitness of allozyme variants in Drosophila pseudoobscura. I. Selection at the PGM1 and Me-2 loci. Genetics 79: 85-95

Marinkovic, D., Ayala, F. J. (1975b). Fitness of allozyme variants in Drosophila pseudoobscura. II. Selection at the Est5, Odh and Mdh-2 loci. Genet. Res. Camb. 24: 137-149

McAndrew, B. J., Ward, R. D., Beardmore, J. A. (1982). Lack of relationship between morphological variance and enzyme heterozygosity in the plaice, Pleuronectes platessa. Heredity $48: 117-125$

Mitton, J. B., Grant, M. C. (1984). Associations among protein heterozygosity, growth rate, and developmental homeostasis. Ann. Rev. Ecol. Syst. 15: 479-499

Mukai, T., Watanabe, T K., Yamaguchi, O. (1974). The genetic structure of natural populations of Drosophila

This article was submitted to the editor melanogaster. XII. Linkage disequilibrium in a large local population. Genetics 77. 771-793

Parsons, P. A. (1974). Male mating speed as a component of fitness in Drosophila. Behav. Genet. 4: 395-404

Polivanov, S., Anderson, W. W (1969). Selection in experimental populations. II. Components of selection and their fluctuations in two populations of Drosophila melanogaster. Genetics 63: 919-932

Prout, T. (1971a). The relation between fitness components and population prediction in Drosophila. I. The estimation of fitness components. Genetics 68: 127-149

Prout, $T$ (1971b). The relation between fitness components and population prediction in Drosophila. II. Population prediction. Genetics 68: 151-167

Quattro, J. M., Vrijenhoek, R. C. (1989). Fitness differences among remnant populations of the endangered Sonoran top minnow. Science, N.Y. 245: 976-978

Rodhouse, P. G., McDonald, J. H., Newell, R. I. E., Koehn, R. K. (1986). Gamete production, somatic growth and multiple-locus enzyme heterozygosity in Mytilus edulis. Mar. Biol. 90: 209-214

Santos, M., Tarrio, R., Zapata, C., Alvarez, G. (1986). Sexual selection on chromosomal polymorphism in Drosophila subobscura. Heredity 57: 161-169

Schaal, B. A., Levin, D. A. (1976). The demographic genetics of Liatris cylindracea Michx. (Compositae). Am. Nat. 110: $191-206$

Smouse, P. E. (1986). The fitness consequences of multiplelocus heterozygosity under the multiplicative overdominance and inbreeding depression models. Evolution 40 : 946-957

Sokal, R. R., Rohlf, F. J. (1981). Biometry. W. H. Freeman, San Francisco

Spieth, H., Ringo, J. M. (1983). Mating behavior and sexual isolation in Drosophila. In: Ashburner, M., Carson, H. L., Thompson, J. N. Jr (eds.) The genetics and biology of Drosophila, Vol. 3c. Academic Press, New York, p. 223-284

Sved, J. A., Ayala, F. J. (1970). A population cage test for heterosis in Drosophila pseudoobscura. Genetics 66: 97-113

Zouros, E., Foltz, D. W. (1987). The use of allelic isozyme variation for the study of heterosis. Isozymes Curr Topics biol. Med. Res 15: 1-60

Zouros, E., Singh, S. M., Foltz, D. W., Mallet, A. L. (1983). Postsettlement viability in the American oyster (Crassostrea virginica): an overdominant phenotype. Genet. Res. 41 $259-270$

Zouros, E., Singh, S. M., Miles, H. E. (1980). Growth rate in oysters: an overdominant phenotype and its possible explanations. Evolution 34: 856-867

Manuscript first received: July 28, 1989

Revised version accepted: January 19, 1990 